\title{
CME quiz discussion
}

\section{Brief Summary}

Indicated only for use as a short-term adjunct in the management of exogenous obesity.

INDICATION: FASTIN is indicated in the management of exogenous obesity as a short term (a few weeks) adjunct in a regimen of weight reduction based on caloric restriction. The limited usefulness of agents of this class (see ACTIONS) should be measured against possible risk factors inherent in their use such as those described below.

CONTRAINDICATIONS: Advanced arteriosclerosis. symptomatic cardiovascular disease. moderate to severe hypertension, hyperthyroidism. known hypersensitivity. or idiosyncrasy to the sympathomimetic amines. glaucoma.

Agitated states. Patients with a history of drug abuse. During or within 14 days following the administration of monoamine oxidase inhibitors (hypertensive crises may result). WARNINGS: Tolerance to the anorectic effect usually develops within a few weeks. When this occurs, the recommended dose should not be exceeded in an attempt to ncrease the effect; rather, the drug should be discontinued. FASTIN may impair the ability of the patient to engage in potentially hazardous activities such as operating machinery or driving a motor vehicle: the patient should

therefore be cautioned accordingly. pharmacologically to the amphetamines. Amphetamines and related stimulant drugs have been extensively abused. and the possibility of abuse of FASTIN should be kept in mind when evaluating the desirability of including a drug as part of a weight reduction program. Abuse of amphetamnes and related drugs may be associated with intense psycho. logical dependence and severe social dysfunction. There are reports of patients who have increased the dosage to many times that recommended Abrupt cessation following prolonged high dosage administration results in extreme fatigue and mental depression: changes are also noted on the sleep EEG. Manifestations of chronic intoxication with anorectic drugs include severe dermatoses, marked insom. nia. irritability. hyperactivity. and personality changes. The most-severe manifestation of chronic intoxications is psy. chosis, often clinically indistinguishable from schizophrenia Usage in Pregnancy: Sate use in pregnancy has not been established. Use of FASTIN by women who are or who may become pregnant. and those in the first trimester of preg. nancy, requires that the potential benefit be weighed against the possible hazard to mother and infant.

Usage in Children: FASTIN is not recommended for use in children under 12 years of age

Usage with Alcohol: Concomitant use of alcohol with FASTIN may result in an adverse drug interaction.

PRECAUTIONS: Caution is to be exercised in prescribing FASTIN for patients with even mild hypertension

Insulin requirements in diabetes mellitus may be altered in association with the use of FASTIN and the concomitan dietary regimen.

FASTIN may decrease the hypotensive effect of guanethidine.

The least amount feasible should be prescribed or dispensed at one time in order to minimize the possibility of overdosage

ADVERSE REACTIONS: Cardiovascular: Palpitation tachycardia, elevation of blood pressure

Central Nervous System: Overstimulation, restlessness. dizziness. insomnia, euphoria, dysphoria, tremor, headache rarely psychotic episodes at recommended doses.

Gastrointestinal: Dryness of the mouth, unpleasant taste. diarrhea, constipation, other gastrointestinal disturbances.

Allergic: Urticaria

Endocrine: Impotence, changes in libido

DOSAGE AND ADMINISTRATION: Exogenous Obesity One capsule at approximately 2 hours after breakfast for appetite control. Late evening medication should be avoided because of the possibility of resulting insomnia.

Administration of one capsule $(30 \mathrm{mg})$ daily has been found to be adequate in depression of the appetite for twelve to fourteen hours.

FASTIN is not recommended for use in children under 12 years of age

OVERDOSAGE: Manifestations of acute overdosage with phentermine include restlessness. tremor, hyperreflexia rapid respiration, confusion. assaultiveness, hallucinations panic states. Fatigue and depression usually follow the central stimulation. Cardiovascular effects include arrhythmias. hypertension or hypotension, and circulatory collapse. Gas trointestinal symptoms include nausea, vomiting, diarrhea. and abdominal cramps. Fatal poisoning usually terminates in convulsions and coma.

Management of acute phentermine intoxication is largely symptomatic and includes lavage and sedation with a barbit urate. Experience with hemodialysis or peritoneal dialysis is inadequate to permit recommendations in this regard. Acidification of the urine increases phentermine excretion. Intravenous phentolamine (REGITINE) has been suggested tor possible acute. severe hypertension, if this complicates phentermine overdosage.

CAUTION: Federal law prohibits dispensing without prescription.

HOW SUPPLIED: Blue and clear capsules with blue and white beads containing $30 \mathrm{mg}$ phentermine hydrochloride (equivalent to $24 \mathrm{mg}$ phentermine).

NDC 0029-2205-30

NDC 0029-2205-39.

NDC 0029-2205-31
These discussions relate to the December 1987 JAOA CME quiz.

1. (b). Steingard and associates achieved excellent results with total medial meniscectomy in all their patients. They attribute this to early operation after injury.

2. (a). Patients with anterior ligament tears had little radiographic evidence of damage at postoperative followup despite functional disability. Steingard and coauthors attribute this discrepancy to the fact that the patients led a sedentary lifestyle because of their clinical symptoms.

3. (a). Dipyridamole's major mode of action in the body is that of a potent coronary vasodilator via the release of adenosine by the myocardial cell.

4. (a). Dipyridamole/thallium-201 testing is a safe alternative to dynamic exercise for thallium-201 imaging with comparable sensitivity and specificity.

5. (g). Patency of saphenous vein grafts is related to many factors, including the vessel grafted, native arterial distal disease, run-off, myocardial status, surgical technique, and interval after bypass.

6. (b) By the end of 10 years after bypass surgery, 45 percent of saphenous veins are fully patent.

7. (a). In the series of cases reviewed by Martini and Melamed and surveyed in the literature by Rohwedder and Weatherbee, the majority of multiple lung cancers had identical histologic patterns.

8. (c). Operative resection of mul- tiple synchronous primary lung tumors yields the same prognosis as when there is only one tumor; survival is as good with metachronous primary lung tumors with an interval between resection more than 2 years as when the interval is less than 2 years.

\section{Beecham}





\section{Rapid,unsurpassed relief}

that lets patients stay alert so they can perform at their best
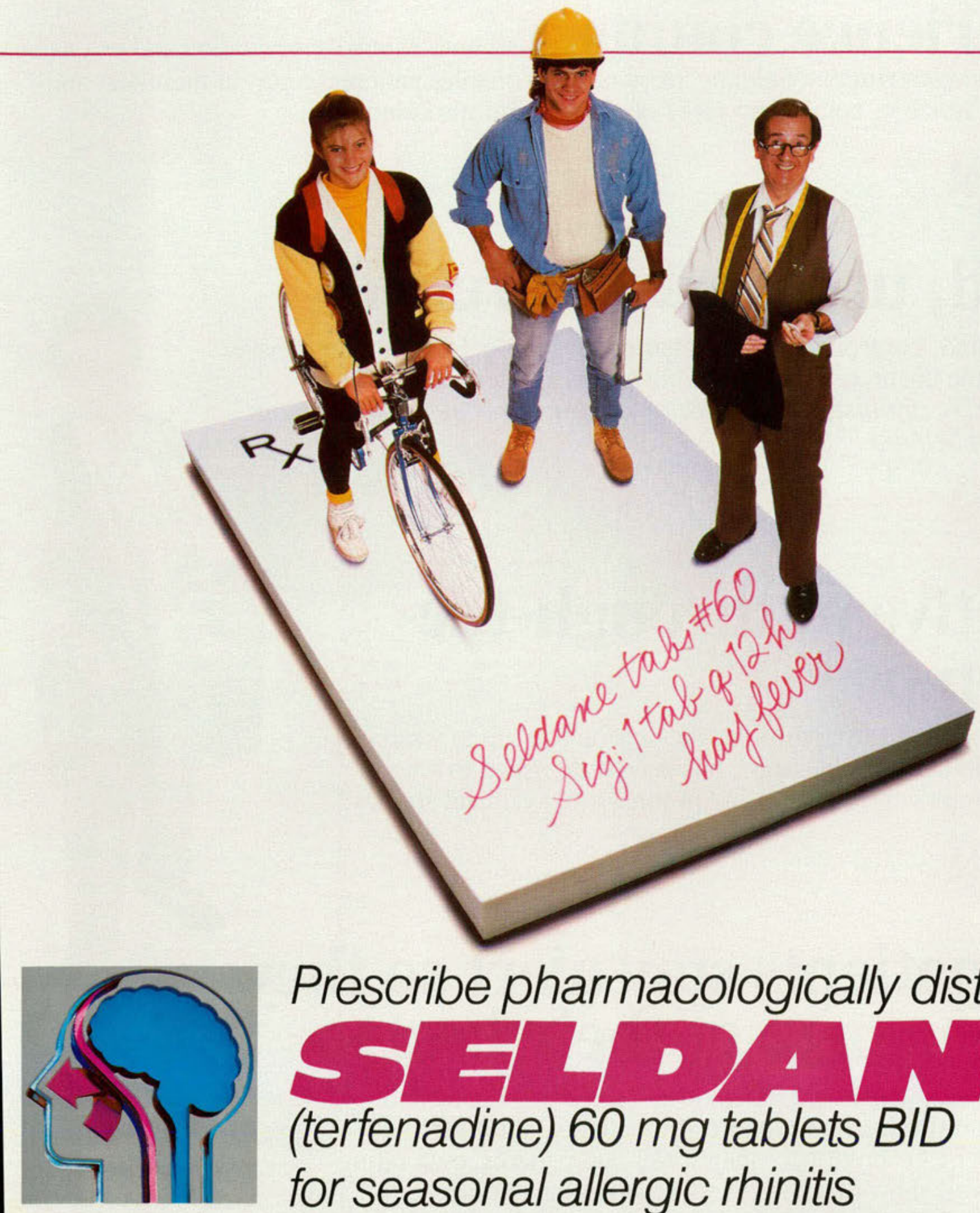

Prescribe pharmacologically distinct

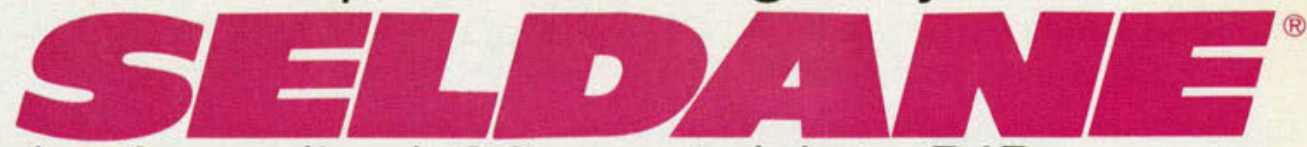

(terfenadine) $60 \mathrm{mg}$ tablets BID for seasonal allergic rhinitis The ideal profile for fast, on-the-job relief 


\section{The \#1 prescribed allergy product in the U.S."... now with more than $\mathbf{3 0}$ million patient-months of experience worldwide}

Experience counts. And both extensive evaluation and extensive experience have shown that Seldane" (terfenadine) enables patients to stay at their best and also get fast, reliable, convenient relief of allergic rhinitis symptoms.

\section{PRONIEN}

\section{Rapid, unsurpassed relief}

22 double-blind, controlled clinical studies, involving 3,049 patients, have proven Seldane unsurpassed in relieving seasonal allergic rhinitis symptoms.$^{1-4}$ No antihistamine - past or present-has been proven more effective than Seldane.

\section{PRONIEN}

\section{Effective in through-the-}

\section{season use}

The efficacy of Seldane in through-the-season use (up to 6 months), without development of tolerance, has been established in a widespread U.S. multicenter study, ${ }^{3}$ and in three other clinical studies. ${ }^{5.7}$

\section{PRONIEN}

\section{Lets patients stay alert so they} can perform at their best

Studies using many different techniques-including controlled clinical trials involving more than 1,700 patients, ${ }^{3}$ multiple sleep latency tests, ${ }^{8}$ EEG activity comparisons, ${ }^{9}$ and patients' own ratings of alertness - all show that Seldane is comparable to placebo in EEG activity, drowsiness, ${ }^{*}$ and other CNS effects. (See Prescribing Information for Contraindications, Precautions, and Adverse Reactions.) 


\section{Prescribe pharmacologically distinct}

(terfenadine) $60 \mathrm{mg}$ tablets $B I D$

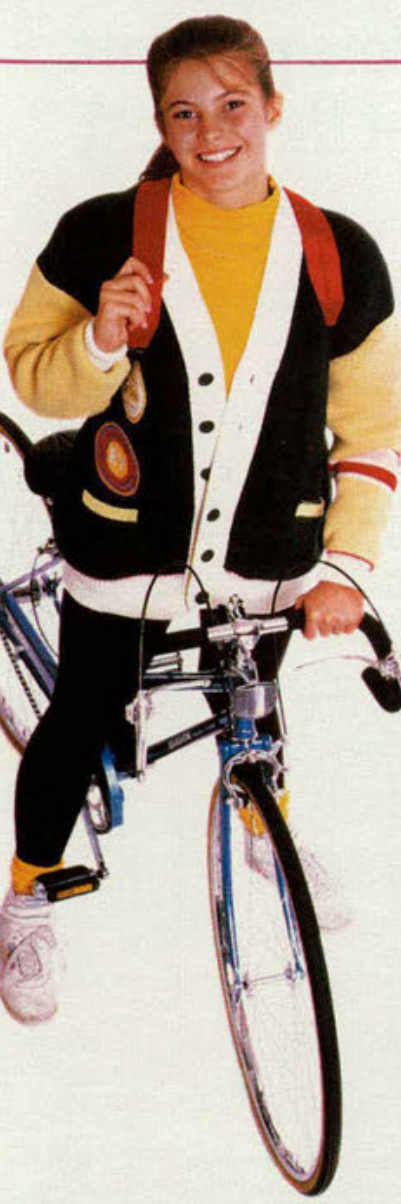

PROVIEN

\section{High physician preference}

$90.7 \%$ of physicians who prescribe for symptoms of seasonal allergic rhinitis have prescribed Seldane. Seldane is the antihistamine prescribed most often by physicians. ${ }^{3 * *}$

\section{PRONIEN}

\section{High patient preference}

$87 \%$ of patients said that Seldane worked as well as or better than allergy medications previously taken. $(63 \%$ said that Seldane worked better. $)^{3}$ In a separate nationwide study, $87 \%$ of patients who started on Seldane continued on Seldane after their first prescription.

*Based on weekly prescription audits of single-entity antihistamines, combination antihistamine/decongestants, nasal steroids, and nasal cromolyn sodium.

${ }^{t}$ The incidence of drowsiness reported with Seldane $60 \mathrm{mg}$ b.i.d. did not differ significantly from placebo, while chlorpheniramine $4 \mathrm{mg}$ t.i.d./q.i.d. produced twice the incidence $[\mathrm{p}<0.02] .{ }^{3}$

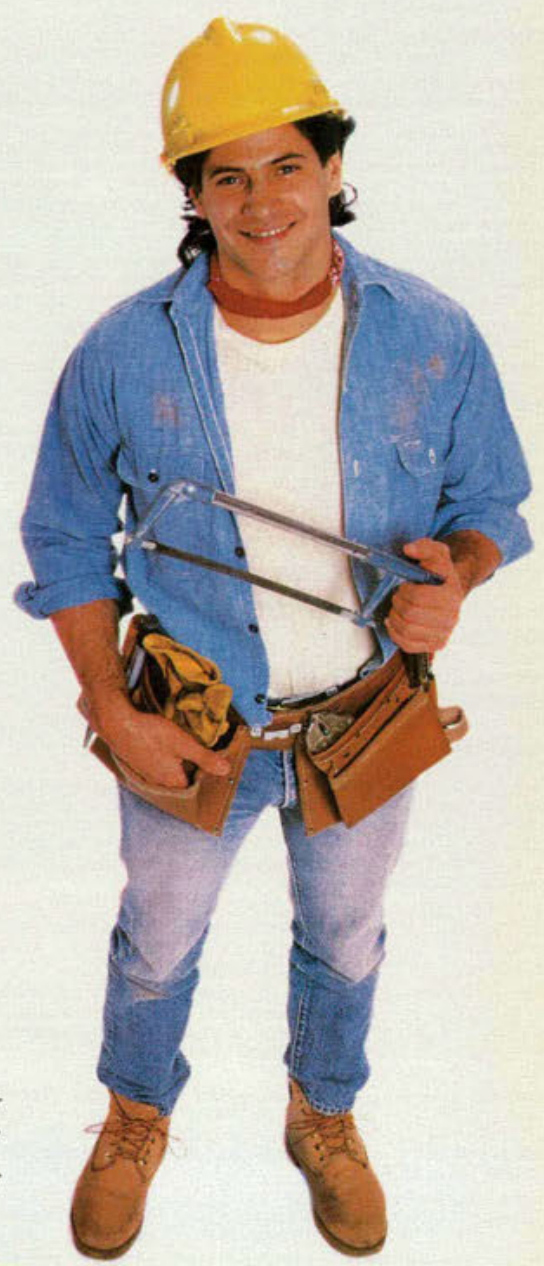

**Based on a major survey of allergists, otorhinolaryngologists, general/family practitioners, pediatricians, internists, and osteopathic physicians, conducted by Opinion Research Corporation of Princeton, N.J., and utilizing a projectable national sampling of 395 physicians. 


\section{New Osteopathic Film a Hit With the Critics}

66 Our state public relations committee sees potential use for this film both in employee orientation and in consumer education by local osteopathic physicians. The film does a good job of illustrating the scope of practice of DOs throughout the country. 99

\section{Steve J. Noone}

Executive Director, Indiana Association of Osteopathic Physicians \& Surgeons

66 Just what the general public needs to see. This film portrays - skillfully - the differences between osteopathic and allopathic medicine, as well as the intrinsic benefits of the holistic 'hands on' approach to health care. 99

\section{Sherry Arnstein \\ Executive Director, American Association of Colleges of Osteopathic Medicine}

66 With the scarcity of material with which to market the osteopathic profession, this production stands out as a 'must have' tool for hospital and medical staff marketing. 99

Frank Engler, Jr

Vice-president, American

Osteopathic Hospital

Association

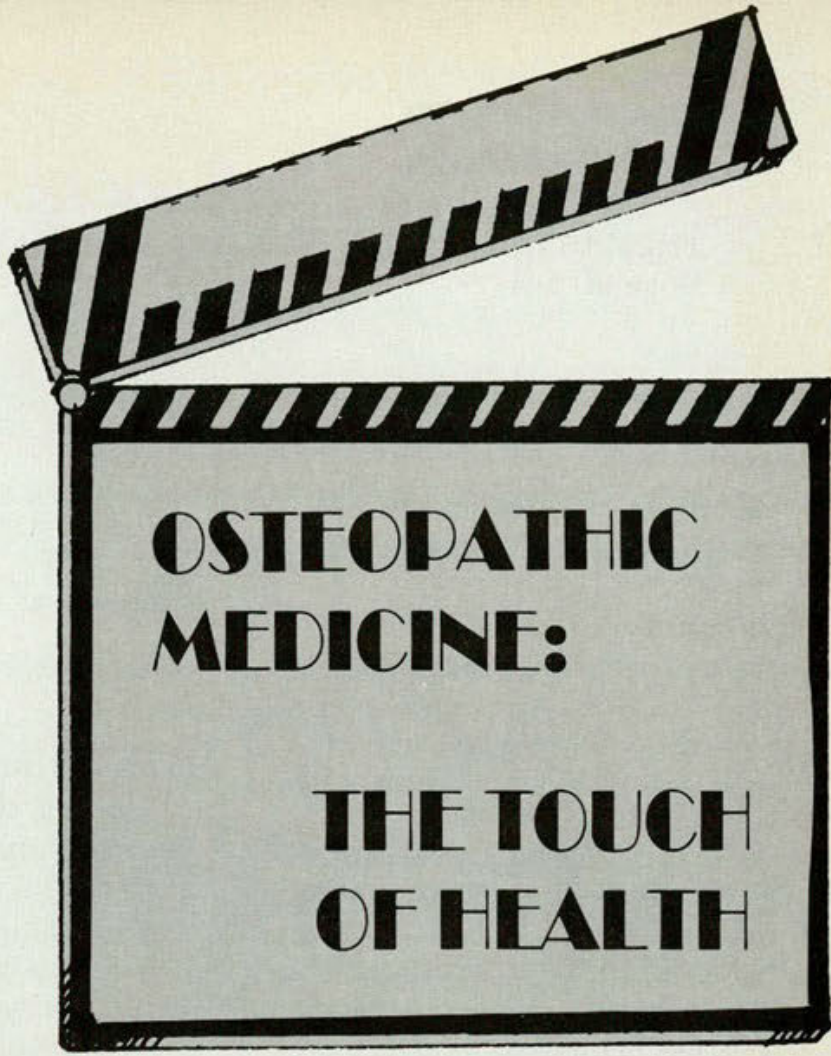

66I used it at an open house for our local Chamber of Commerce when I opened my new office. I was pleased with it, and so was everyone else who viewed it. 99

Fred Leslie, DO

Seminole, Florida
${ }^{66}$ As a PR professional, I'm pleased to have a new tool like this film to use in my efforts here. 99
Ricki Carruth
Director of
Communications,
West Virginia School
of Osteopathic Medicine

Line up an audience now and call:

Film Depository

(800) 345-6522

Rental fee: only $\$ 20$

Produced by the American Osteopathic Associatic in cooperation with

the Philadelphia College of Osteopathic Medicin 
